\title{
Cardiovascular involvement after liver transplantation: role of non-alcoholic fatty liver disease and non-alcoholic steatohepatitis
}

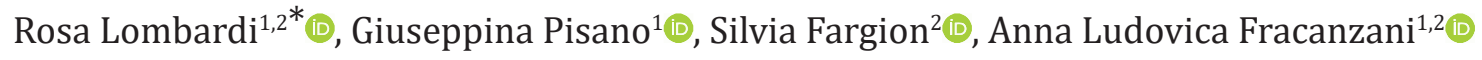 \\ ${ }^{1}$ General Medicine and Metabolic Diseases, Fondazione IRCCS Ca' Granda Ospedale Maggiore Policlinico, 20122 Milan, Italy \\ ${ }^{2}$ Department of Pathophysiology and Transplantation, University of the Study of Milan, 20122 Milan, Italy \\ ${ }^{3}$ Amity Institute of Biotechnology, Amity University Haryana, Manesar, Haryana 122413, India
}

*Correspondence: Rosa Lombardi, Department of Pathophysiology and Transplantation, Fondazione IRCCS Ca' Granda Ospedale Maggiore Policlinico, University of the Study of Milan, Via F. Sforza 35, 20122 Milano, Italy. rosa.lombardi@unimi.it

Academic Editor: Lindsay A. Farrer, Boston University School of Medicine, USA

Received: October 20, 2020 Accepted: November 21, 2020 Published: February 28, 2021

Cite this article: Lombardi R, Pisano G, Fargion S, Fracanzani AL. Cardiovascular involvement after liver transplantation: role of NAFLD and NASH. Explor Med. 2021;2:20-38 https://doi.org/10.37349/emed.2021.00030

\begin{abstract}
Patients submitted to liver transplantation (LT) are exposed to high risk of cardiovascular (CV) complications which are the main determinants of both short-term and long-term morbidity and mortality in LT. Nonalcoholic fatty liver disease (NAFLD) is a very frequent condition in general population and is associated with a high risk of cardiovascular disease (CVD) which represents the first cause of death of these patients. NAFLD is predicted to become the first indication to LT and nowadays is also frequently detected in patients submitted to LT for other indications. Thus, the risk of CVD in patients submitted to LT is forecasted to increase in the next years. In this review the extent of CV involvement in patients submitted to LT and the role of NAFLD, either recurring after transplantation or as de novo presentation, in increasing CV risk is analysed. The risk of developing metabolic alterations, including diabetes, hypertension, dyslipidemia and weight gain, all manifestations of metabolic syndrome, occurring in the first months after LT, is depicted. The different presentations of cardiac involvement, represented by early atherosclerosis, coronary artery disease, heart failure and arrhythmias in patients with NAFLD submitted to LT is described. In addition, the tools to detect cardiac alterations either before or after LT is reported providing the possibility for an early diagnosis of CVD and an early therapy able to reduce morbidity and mortality for these diseases. The need for long-term concerted multidisciplinary activity with dietary counseling and exercise combined with drug treatment of all manifestations of metabolic syndrome is emphasized.
\end{abstract}

\section{Keywords}

Orthotopic liver transplantation, cirrhotic cardiomyopathy, cardiovascular mortality, subclinical atherosclerosis, fatty liver

\footnotetext{
(C) The Author(s) 2021. This is an Open Access article licensed under a Creative Commons Attribution 4.0 International License (https://creativecommons.org/licenses/by/4.0/), which permits unrestricted use, sharing, adaptation, distribution and reproduction in any medium or format, for any purpose, even commercially, as long as you give appropriate credit to the original author(s) and the source, provide a link to the Creative Commons license, and indicate if changes were made.
} 


\section{Introduction}

Liver transplantation (LT), the only effective treatment for end stage liver disease, has spread in the past 50 years in Europe, plateauing in recent years, with about 7,300 LTs performed in Europe and 8,000 in the United States annually [1, 2]. Non-alcoholic fatty liver disease (NAFLD) [3] is becoming the leading cause of LT in the USA, and rate of LT caused by NAFLD is likely to further increase in next years as a consequence of metabolic syndrome (MS) diffusion and the absence of established therapies [2]. Survival rates from United Network for Organ Sharing registry at 1, 5 and 10 years are approximately $85 \%, 70 \%$ and 50\% [1, 4], with the critical period for post LT outcome represented by the first year during which $46 \%$ of deaths occur, nearly $60 \%$ of which within 6 months [1]. More than 10\% of LT recipients have cardiovascular disease (CVD) which together with hepatic and cancer, are the most common causes of death after LT [5]. Nowadays, despite the marked improvement in immunosuppressive therapies and organ preservation techniques [6] post-transplant death rate remains elevated because of CVD.

The aim of this review is to clarify the extent of cardiovascular (CV) involvement in post LT patients, defining the role of NAFLD in increasing CV risk. Indeed, as depicted in Figure 1, beyond being a cause of LT, NAFLD can reappear after LT (recurrent NAFLD) and even arise after LT in patients without steatosis before transplantation (NAFLD). Reported data in this review were identified by search and selection database of MEDLINE, Google Scholar, PubMed, Elsevier, by using the search term "LT" combined with "CV risk" and "NAFLD". Relevant articles were selected. Review articles are cited to provide more details and references.
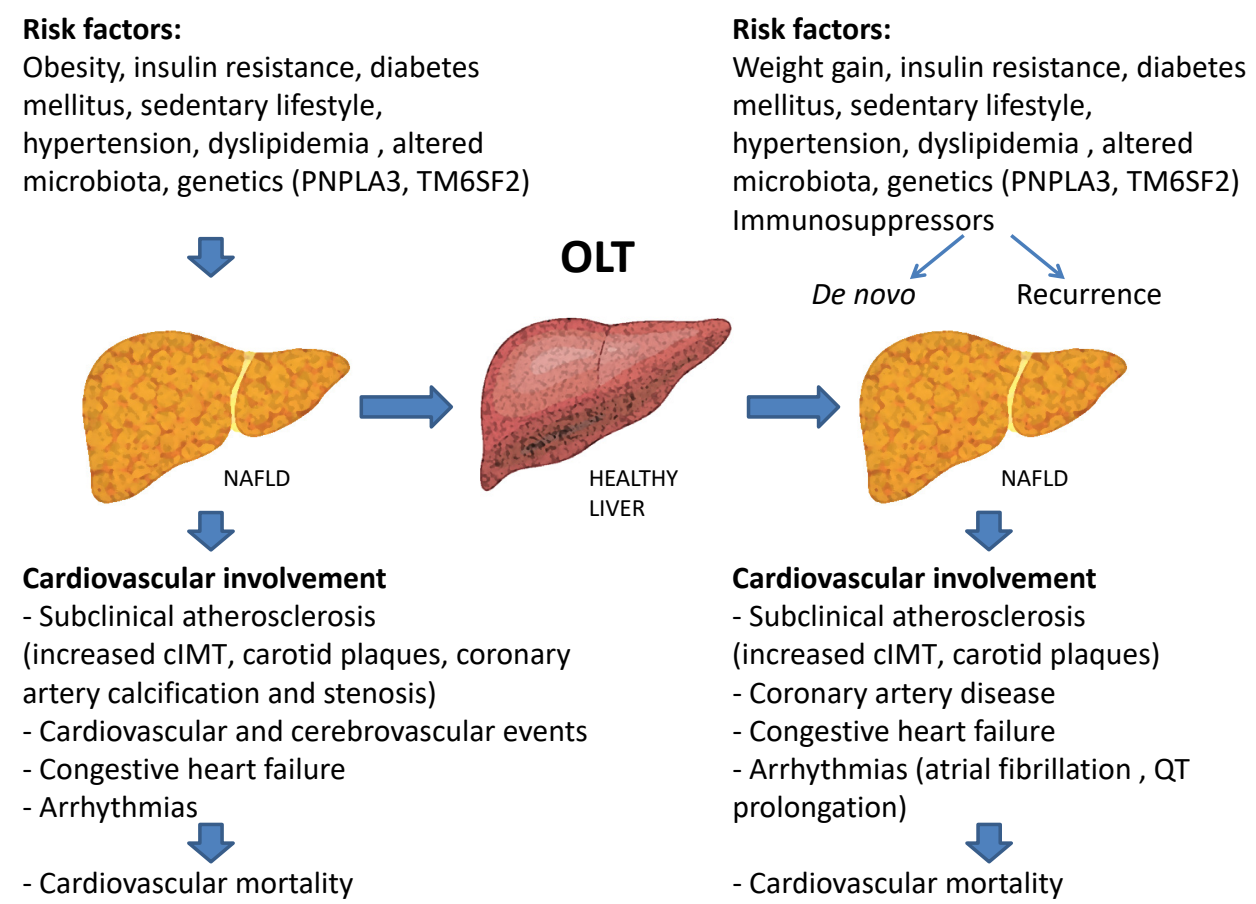

Figure 1. Risk factors for the development of NAFLD and cardiovascular damage before and after liver transplantation. Obesity, insulin resistance, diabetes mellitus, hypertension, dyslipidemia, sedentary lifestyle, altered microbiota and genetics [patatinlike phospholipase domain containing 3 (PNPLA3) and transmembrane 6 superfamily member 2 (TM6SF2)] favor the onset of NAFLD. NAFLD could progress into advanced liver disease requiring liver transplantation (LT). However, NAFLD can develop even after liver transplantation, sustained by the same pathogenetic factors of the pre-LT. Either in the pre-LT or post-LT period NAFLD exposes patients to high cardiovascular morbidity and mortality

\section{NAFLD and CV risk}

The link between NAFLD and CV disease is well established since both diseases share many metabolic risk factors such as obesity, insulin resistance, type 2 diabetes (T2DM), hypertension, dyslipidemia, as well as a sedentary lifestyle, genetic predisposition (PNPLA3 and TM6SF2 gene) [7-9] and gut microbiota impairment which favours either hepatic steatosis or inflammation and atherosclerosis [10,11].

NAFLD is a risk factor for either subclinical or established CVD and mortality. In fact, a higher prevalence of subclinical atherosclerosis [12] represented by increased carotid artery intima-media thickness (cIMT) 
and presence of carotid plaques [13], and coronary artery calcification and significant coronary stenosis at coronarography [14] have been demonstrated. Interestingly, there is a relation between severity of liver and CV damage, being a more advanced liver disease associated with a more serious vascular damage $[11,15]$. In addition, NAFLD patients experience more CV events than the overall population. In 2016, Fracanzani et al. [16] evaluated the incidence of cardiac and cerebrovascular events in patients with NAFLD and in a control cohort, followed-up over a 10-year period, showing a higher prevalence of CV events in the NAFLD group [15]. In addition, NAFLD subjects are more likely to develop congestive heart failure and cardiac arrhythmias [mainly atrial fibrillation and corrected QT interval (QTc) interval prolongation] compared to the general population [17].

As a consequence, CV-related death appears to be the leading cause of mortality in patients with NAFLD, as demonstrated by Ekstedt et al. [18], who evaluated mortality from all causes in 229 patients over a period of 30 years.

Additionally, T2DM and morbid obesity, which are very prevalent in NAFLD, have been reported to impact on death/removal from the LT waiting list of patients with liver disease of different etiology [19]. On the basis of this evidence, screening for CV disease all patients with NAFLD, irrespectively of the presence of other traditional risk factors [20] is highly recommended by the European Association for the Study of the Liver [21].

\section{Differences by gender}

Recent literature data indicate a different gender-related presentation of NAFLD. The prevalence of NAFLD is higher in males compared to premenopausal women becoming comparable after menopause, when women tend to gain weight, to have a different distribution of fat, mainly visceral, with an increased risk to develop NAFLD and CVD [22, 23].

Data on the prevalence of $\mathrm{CV}$ complications are controversial and not conclusive. An independent male association with coronary artery calcifications has been described in general population [13]. A large Korean cross-sectional study reported that men had a higher prevalence of NAFLD, carotid plaque and cIMT values [24]. On the contrary data obtained from German and Austrian populations indicate a close association between NAFLD and CV events (myocardial infarction and coronary heart disease) regardless of gender $[25,26]$.

In postmenopausal women a correlation between NAFLD (evaluated by computer tomography) and prevalence of coronary artery calcifications has been described, however the association was lost after correction for the known CVD risk factors [27]. Finally, although not conclusive, literature data suggest that while in the general population female sex appears to be protective for ischemic CV events, in women with NAFLD is not [28]. Indeed, in a recent meta-analysis considering 108,711 patients with NAFLD (44\% females) all-cause mortality was about 1.5 times higher in women than in men and CV events 2 times higher [29].

Future studies on the different ways of evaluating metabolic alterations in women compared to men are needed in consideration of the increased number of transplants performed in women. In fact, in recent years, non-alcoholic steatohepatitis (NASH) represents the leading cause of transplantation in the female population [30, 31].

\section{CVD post LT}

Despite it is clear that CV complications determine either short-term or long-term morbidity and mortality in LT $[9,32,33]$, studies exploring prevalence and risk factors for specific CV events after LT are lacking and often CV assessment is evaluated as composite including coronary artery disease (CAD), heart failure and arrhythmias without considering cirrhosis associated cardiomyopathy. Also in a recent systematic review of 29 studies including 57,493 patients, definitions of CV outcomes were highly inconsistent [34] and only 3 studies evaluated CV-related mortality [5, 9, 35].

We reported the most consistent data on the onset of CVD post LT and the role of NAFLD in this setting as depicted in Table 1. 


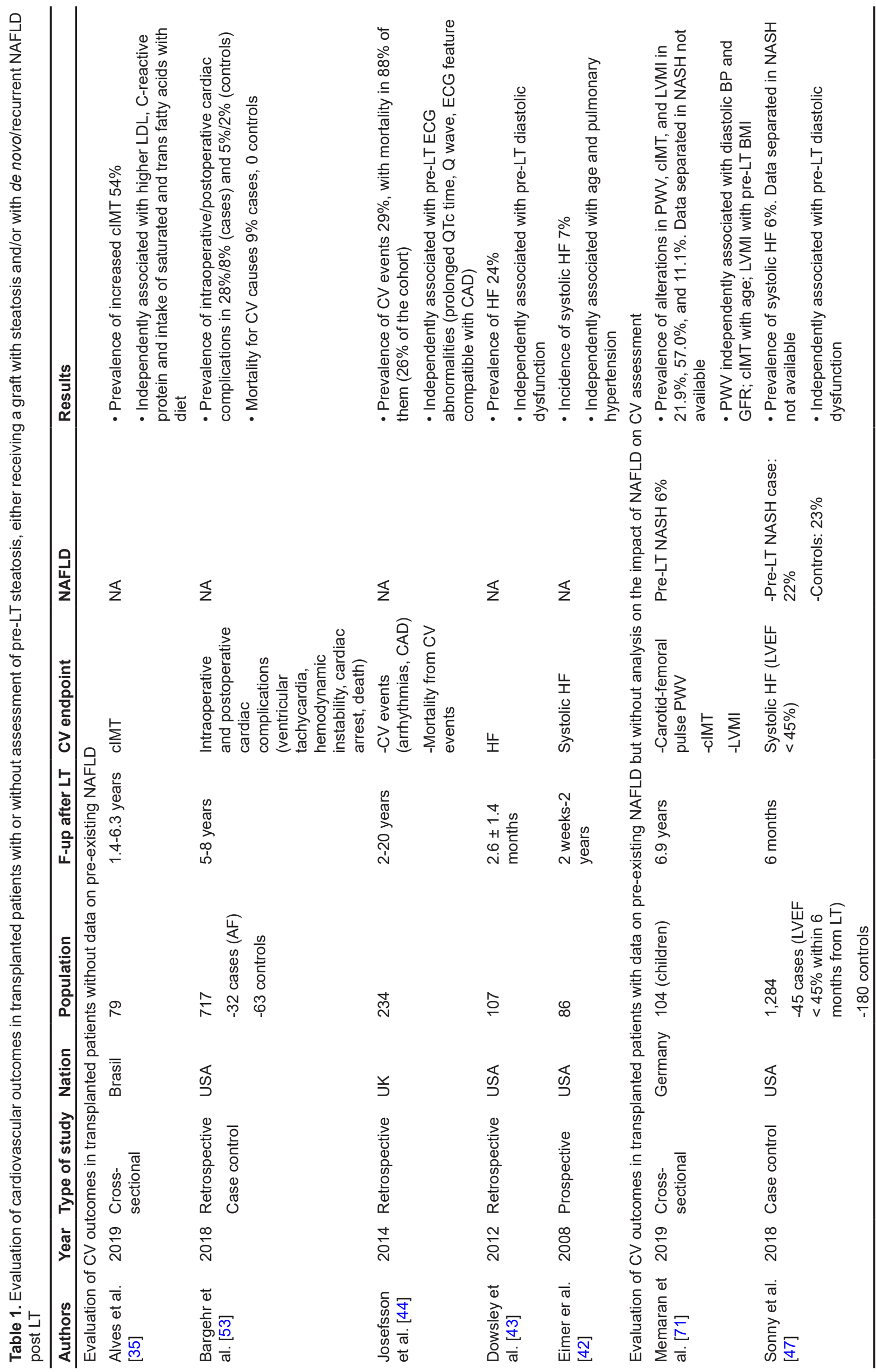




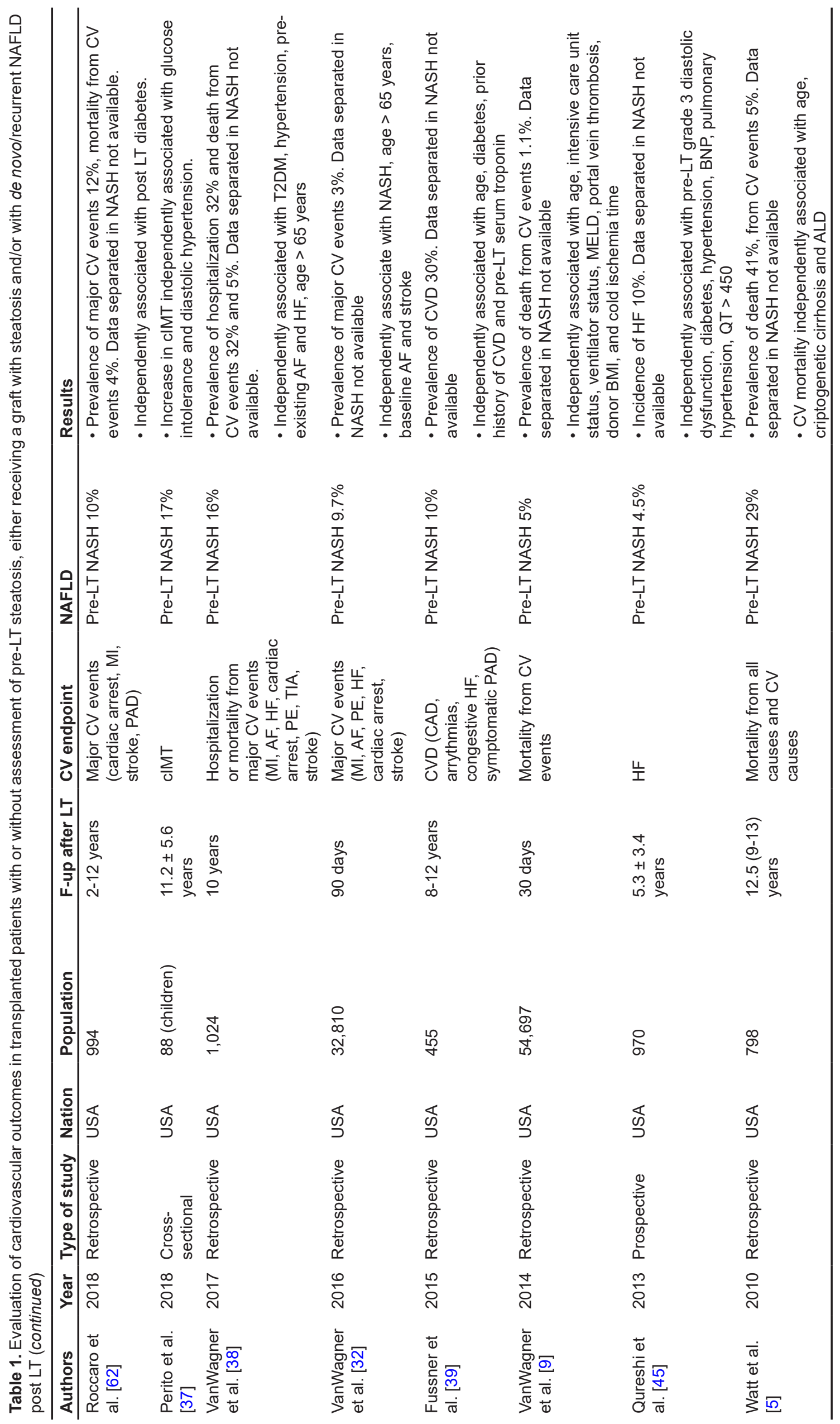




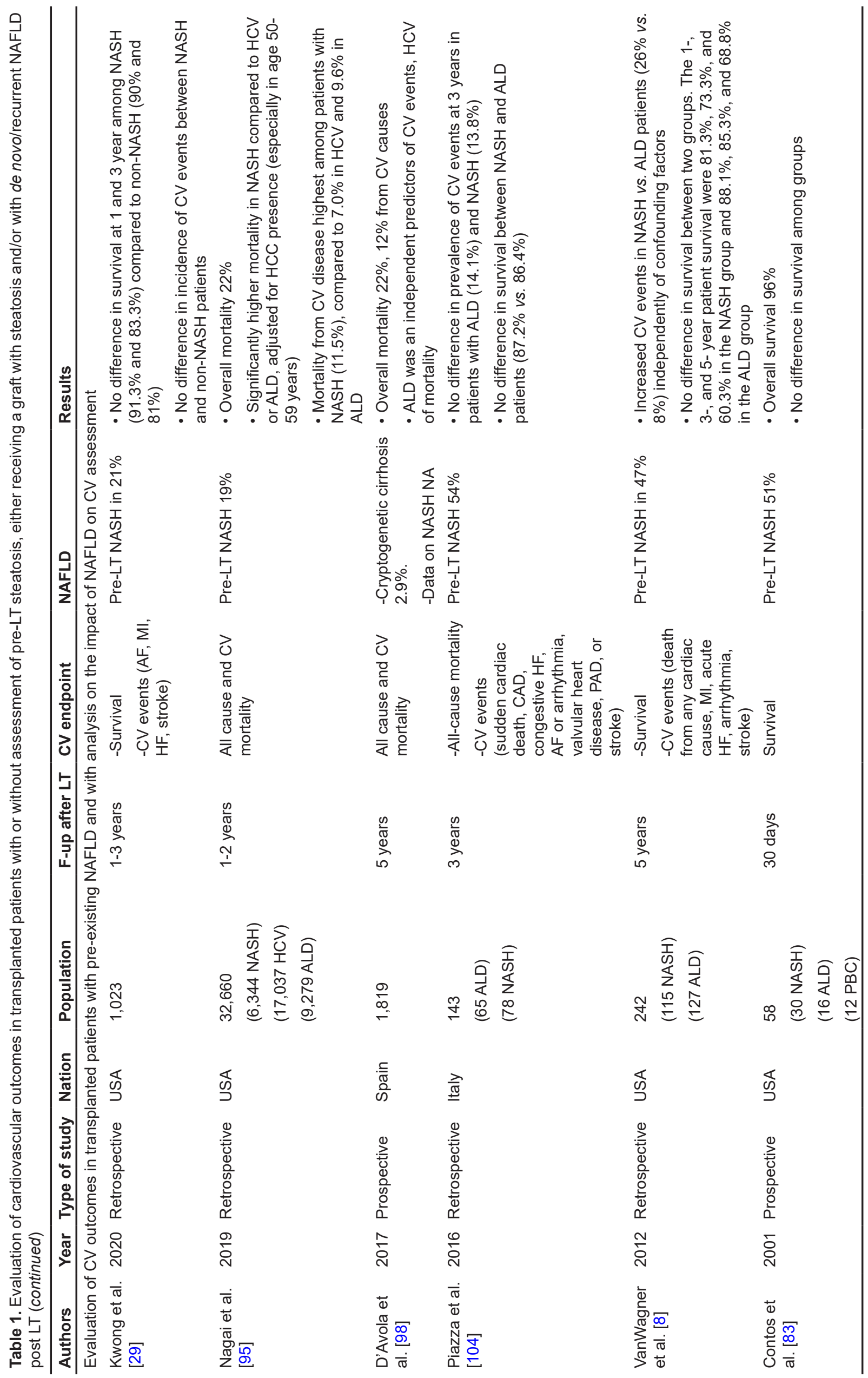




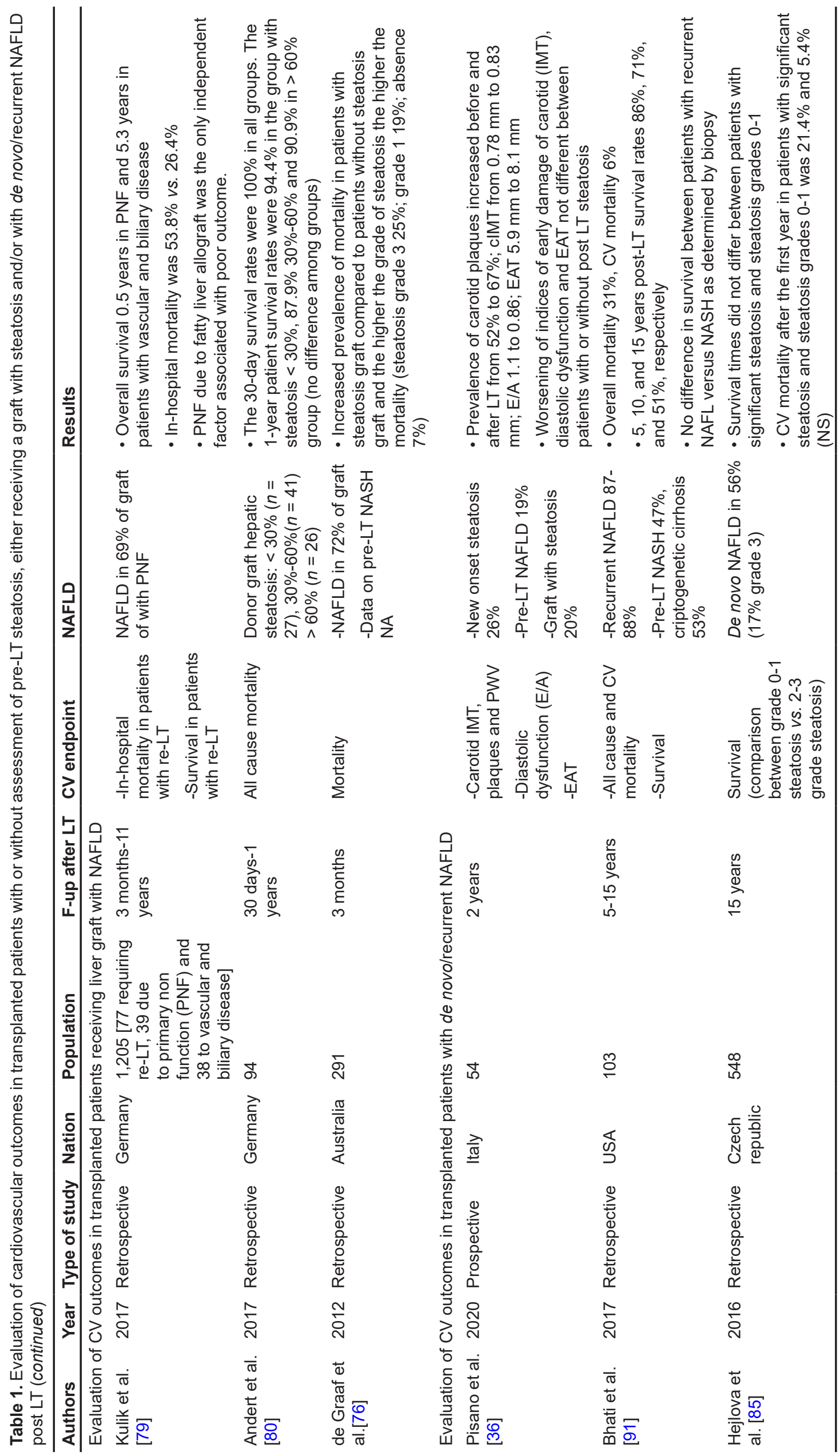




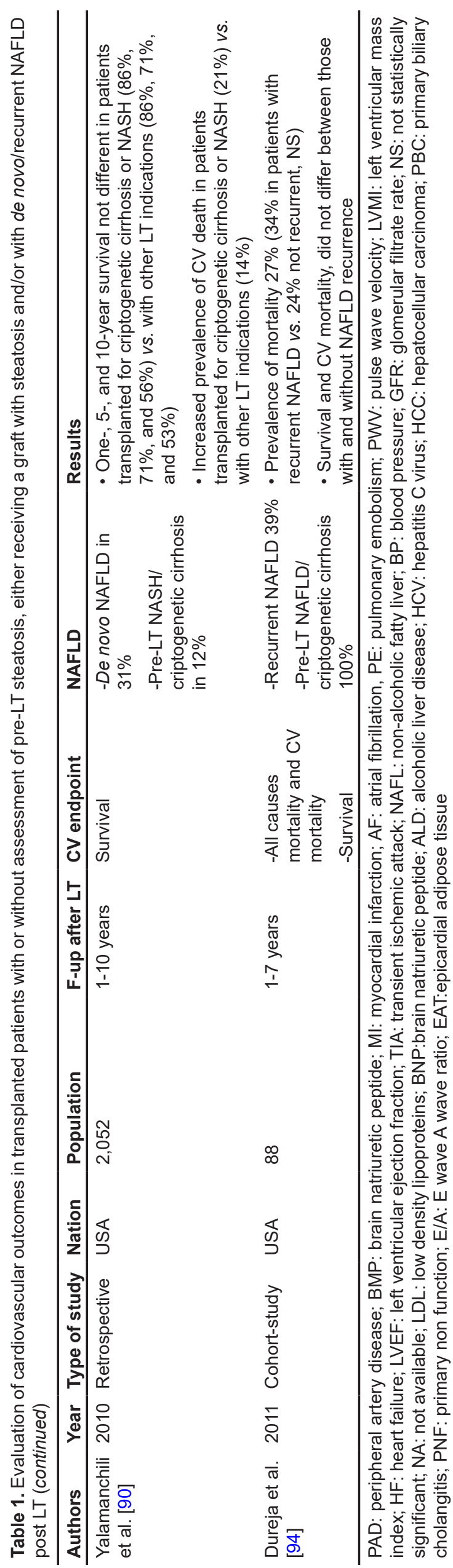




\section{Early atherosclerosis post LT}

The presence of early atherosclerosis assessed by either cIMT or by the presence of carotid plaques in patients undergoing LT has been recently documented not only in adults but also in pediatric patients. Indeed, endothelial damage has been demonstrated to onset very early after LT, with increase in carotid IMT and stiffness after 6 months from transplant [36, 37], both in children and adolescents [38]. In adults, presence of subclinical atherosclerosis was associated with an increased prevalence of features of MS, namely diabetes, hypertension and dyslipidemia [37].

\section{CAD post LT}

CAD is the most studied CVD in patients post LT because of its highly negative prognostic impact on patient's survival. In fact, a study following up patients post LT for 10 years showed an incidence of CAD, either with or without myocardial infarction, of approximately $40 \%$, with increasing incidence over time (i.e. $15 \%$ at 3 years and $30 \%$ at 8 years post LT). In particular, among all patients who experienced CAD, $12 \%$ underwent a revascularization procedure in the first year after LT [39]. Interestingly, in subjects without pre-existing CVD, pre-transplant troponin I elevation ( $>0.07 \mathrm{ng} / \mathrm{mL}$ ) before LT was predictive of occurrence of CVD after LT [40], as well as of higher mortality in the first month post-transplant, possibly indicating that even subtle undiagnosed CAD (i.e. subclinical or microvascular), could predispose to future CV events [41].

\section{Heart failure post LT}

Heart failure after LT is often reported, with transient cardiac decompensation occurring in $7-43 \%$ of patients during postoperative period [42-49]. Cirrhotic cardiomyopathy (CCM), described as a cardiac dysfunction (systolic or diastolic) in patients with end-stage liver disease without prior heart disease, includes a hyperdynamic circulation, a blend of systolic and diastolic dysfunction, along with prolonged ventricular repolarization, and blunted inotropic and chronotropic response to stress [32]. CCM is possibly due to fibrosis and hypertrophy of the myocardium and to subendocardial oedema [50,51].

Pre-transplant diastolic dysfunction seems to be linked with graft rejection and failure [47], posttransplant mortality $[44,47]$ and post-transplant systolic heart failure $[44,48]$. Indeed, in the absence of an overt clinical manifestation it is often challenging to establish whether subclinical CV damage was already present before the transplant or whether it is a new onset. In addition, some cardiac alterations of patients with cirrhosis are due to coexisting obesity or diabetes, thus making the diagnosis of CCM even more confusing. The recent availability of new methods for the assessment of CCM in patients with end-stage liver disease modified the criteria for the diagnosis and follow-up of the patients before and after LT [52].

\section{Dysrhythmia post LT}

A prolonged QT interval is very frequently reported in the ECG of patients listed for LT [50], and it is associated with a high risk of sudden cardiac death (SCD), especially when the interval is more than $0.5 \mathrm{~s}$. On the other hand, the prognostic role of prolonged QTc in cirrhotic patients not requiring LT is not defined [50]. However, QTc often normalizes after LT [50], whereas its persistent prolongation is associated with an increased rate of post LT fatal and non-fatal CV events [45, 53].

Among all tachyarrhythmias, atrial fibrillation, either before or after LT, is the most widely observed. Its prevalence in LT candidates ranges from $1.4 \%$ to $6 \%[33,54]$ and it is associated with post LT increased CV complications, graft failure and mortality [33, 54, 55]. Interestingly increased long-term risk of atrial fibrillation has recently been described in NAFLD patients [56] and more severe the liver disease (i.e. NASH or cirrhosis) higher its prevalence. Few data are available on the development of atrial fibrillation after LT in patients with cirrhosis of which the etiology is not metabolic.

\section{Assessment of CV risk post LT}

In order to define the prognostic role of $\mathrm{CV}$ complications, CV risk assessment is essential in LT recipients, so that scores predictive of both early and late $\mathrm{CV}$ atherosclerotic complications are accumulating. 
Among predictors of short term occurrence (i.e. within 1 year after LT) of CV events, the most widely used is the CV risk in orthotopic liver transplantation (OLT), which is based on pre-LT demographic, social, and clinical variables [57].

Conversely, scores for the assessment of the risk of late atherosclerotic complications tailored for LT recipients are missing, so that currently those applied in the general population are used, including the Framingham general CVD score (FRS) [58], the pooled cohort equations (PCEs) [59], the Reynolds Risk Score [60], the Prospective Cardiovascular Münster Study (PROCAM) [61] and the Systematic Coronary Risk Evaluation Project (SCORE) [62]. On the contrary, no validated scores for the prediction of heart failure after LT are available.

Along with risk scores, also the presence of metabolic comorbidities may help clinicians in stratifying CV risk in LT recipients. In fact, T2DM, especially if persistent after LT, has been demonstrated a key prognostic factor for CV morbidity, with an incidence of major CV events of $13 \%$ and $27 \%$ at 5 and 10 years [63].

Unfortunately, clear guidelines about CV follow-up after LT are missing, as well as about evaluation of subclinical CV changes. Usually, the follow-up consists of a clinical and biochemical control performed semesterly or annually and referral to a specialist only in the presence of hypertension or diabetes. If on one hand the onset CV events after LT has been widely studied, on the other hand only few studies and a meta-analysis [37, 64-72] demonstrated an increase in subclinical atherosclerosis after solid organ transplantation.

\section{Steatosis, LT and CVD}

Patients who undergo LT can receive a liver graft with steatosis, can develop steatosis which was absent before LT (steatosis) and can have recurrence of steatosis in the new liver (patients with NAFLD pre-LT).

\section{Liver graft with steatosis}

Given the increased prevalence of NAFLD worldwide, along with a shortened organ pool donation in many countries, utilization of donor grafts with hepatic steatosis is now more common [73]. Hepatic steatosis is seen in the biopsies of a consistent percentage of potential liver donors, reaching up to $75 \%$ if overweight is present [74].

As a consequence of reperfusion, alterations in microcirculation and hepatocytes are induced by steatosis in the graft, with consequent necrosis and impaired regenerative processes [75, 76]. As a result, hepatic steatosis in donor livers exposes recipients to increased morbidity and mortality. Necessity of intensive care unit, longer hospitalization, as well as increased risk of graft failure [77-79], especially for steatosis in more than $60 \%$ of the graft [79-82], is usually observed. Viceversa, presence of moderate steatosis seems to affect significantly neither the long-term liver-related outcome [83] nor the CV outcome [37].

\section{De novo steatosis}

The term de novo NAFLD indicates the occurrence of steatosis in the transplanted livers of patients who did not have steatosis before LT, its prevalence ranging from $25 \%$ to $60 \%$ [37, 84-86] depending on follow-up duration and populations studied. Interestingly, prevalence of de novo steatosis increases over time (30\% at 1 year up to nearly $50 \%$ after 10 years) with $5-10 \%$ progressing towards NASH and $2.5 \%$ to cirrhosis [85-89].

\section{Risk factors for de novo steatosis}

Risk factors for de novo steatosis include presence in LT recipients of sarcopenia and features of MS (especially insulin resistance, hypertension and obesity), tacrolimus based immunosuppressive therapy, hepatitis $\mathrm{C}$ virus and genetic predisposition as the genotype [83-85], as well as hypoadiponectinemia and high levels of free fatty acids [90]. Indeed, in transplanted patients who develop de novo steatosis, CV events are common with nearly $40 \%$ of transplant recipients experiencing an event within 10 years, one-third occurring within the first year. 


\section{Recurrence of steatosis}

Recurrent NAFLD is the onset of steatosis in the graft of a patient needing LT for the liver complications of hepatic steatosis in a dysmetabolic setting, with a recurrence rate of $30-60 \%$ within 1-5 years after LT, and with progression towards NASH of 10-33\% and advanced fibrosis of 5-10\% [91]. Other data report a higher prevalence, with a recurrence rate as high as $90-100 \%$ [84, 92]. Differences in the prevalence of steatosis recurrence are likely related to the diagnostic methodology to assess steatosis, the time from transplant, and presence of pre and post-transplant risk factors.

In addition, patients who need a liver transplant because of metabolic cirrhosis are likely to have recurrence of NAFLD, and classically they present features of MS and pre-existing CV disease [91, 93], thus being exposed to higher CV risk by default $[94,95]$.

De novo and recurrent NAFLD are indeed two distinct entities. In particular, patients with recurrent NAFLD present higher prevalence of obesity and diabetes compared with patient with de novo NAFLD, are more likely to progress to advanced forms of NAFLD, suggesting a more aggressive course of the disease [87], likely because of a longer exposure to metabolic alterations. In addition, it has been reported that steatosis resolves in one-fifth of patients with de novo and only rarely in those with recurrent NAFLD [87]. However, data on the impact of recurrent NAFLD on long-term outcomes are conflicting, some showing a similar overall survival in patients with and without recurrent NAFLD [84, 91, 95], even in the presence of NASH [92], others an increase in mortality, mainly if patients had developed NASH $[83,92,96]$.

Although there are no concordant data on the increase in overall mortality in NAFLD transplant patients compared to those of other etiologies, CV complications after LT are higher in NAFLD patients. In fact, a higher incidence of major cardiac and cerebrovascular events was reported in NAFLD subjects related to age, pre-transplant T2DM and other features of MS and a history of post-transplant CAD [10, 97].

Furthermore, de novo and recurrent steatosis are related to weight gain post LT. Weight gain is observed in almost all patients after 3 months from LT, with patients with pre-transplant NAFLD gaining more weight than non-NAFLD patients [98]. Moreover, new onset obesity was found related with a higher incidence of CV disease [99].

\section{Genetic, LT and CVD}

The interplay between metabolic and genetic factors in the CVD of patients with NAFLD is known [100] conversely the relevance of genetic factors in $\mathrm{CV}$ complications post OLT is still not defined. A dated paper which analyzed the role of the C677T-methylenetetrahydrofolate reductase (MTHFR)-polymorphism on vascular complications in 47 liver transplant recipients reported that this polymorphism was significantly associated with an increased incidence of vascular complications [101]. However, the sample size was small and no other study confirmed these results. In addition, recently variants in the MTHFR gene have been recently demonstrated as not associated with fatty liver disease making unlikely the role of this variant in post OLT CVD [102]. As previously mentioned, genetic factors, including the major genetic determinant of NAFLD, and the TM6SF2 E167K polymorphisms, as well as the membrane-bound $O$-acyltransferase domaincontaining 7 (MBOAT7) genetic variant facilitate NAFLD occurrence before transplant [103].

It is very likely that the same polymorphisms will increase the risk of CVD after OLT. In a small study performed in China it was reported that the coexistence of obesity and positivity for I148M GG was strongly associated with de novo NAFLD occurrence post OLT [104]. Thus, even if longer follow up was not available to assess the risk of CVD in positive patients it can be expected that similarly to patients with NAFLD, transplanted subjects are at higher risk for CVD. It is possible that genetic polymorphisms may even play a major role given the presence of multiple environmental factors, after OLT, increasing CV risk. It will be interesting to define whether carriers of polymorphisms known to facilitate NAFLD occurrence but protect from CVD, such as the TM6SF2 E167K, will reduce the risk of CVD post OLT [100].

In summary, given the epidemic of NAFLD and consequently the fastest growing indication to LT, some authors have evaluated whether NAFLD and NASH per se constitute an increased risk of CVD but results are 
contrasting. Piazza et al. [105] found that NASH is not an independent risk factor for CVD in transplanted patients and a recent meta-analysis including 4,237 transplanted patients, 717 with NASH, from 9 studies [106] confirmed these data. In contrast, another meta-analysis pooling data from 16 observational studies, demonstrated that NAFLD was a risk factor for fatal and nonfatal CV events, and the more advanced the liver disease the higher the risk [107].

Thus, findings are far from being conclusive. While there is a general agreement that the metabolic alterations prevalent in NAFLD patients have an impact on death/removal during the LT waiting list, survival, CV events and renal failure rates were similar in NASH and non-NASH patients undergoing LT [30].

\section{Conclusions}

In conclusion, NAFLD represents one of the main indications for LT, it is often present also in patients in whom the indication for LT recognizes other etiologies and can develop after transplantation. Therefore, NAFLD seems to confer an increased risk of CV morbidity and mortality, mainly when associated with T2DM and MS.

Patients referred to LT for NAFLD-related complications need aggressive management of risk factors before LT to reduce waiting list morbidity/mortality and to reduce post LT CV damage related to de novo development or recurrent NAFLD, weight gain and MS.

Prevention of CVD morbidity and mortality requires long-term concerted multidisciplinary activity with dietary counseling and exercise associated with therapy for hypertension, T2DM and dyslipidemia.

\section{Abbreviations}

CAD: coronary artery disease

CCM: cirrhotic cardiomyopathy

cIMT: carotid artery intima-media thickness

CV: cardiovascular

CVD: cardiovascular disease

LT: liver transplantation

MS: metabolic syndrome

NAFLD: non-alcoholic fatty liver disease

NASH: non-alcoholic steatohepatitis

OLT: orthotopic liver transplantation

PNPLA3: patatin-like phospholipase domain containing 3

T2DM: type 2 diabetes

TM6SF2: transmembrane 6 superfamily member 2

\section{Declarations}

\section{Author contributions}

RL and GP revised the literature, focusing on full text paper regarding CV involvement in post LT patients and role of NAFLD in increasing the CV risk and wrote the draft of the manuscript. SF and ALF were involved in the critical revision of the manuscript to its final form and contributed to the review for important intellectual content.

\section{Conflicts of interest}

The authors declare that they have no conflicts of interest. 


\section{Ethical approval}

Not applicable.

\section{Consent to participate}

Not applicable.

\section{Consent to publication}

Not applicable.

\section{Availability of data and materials}

Not applicable.

\section{Funding}

Not applicable.

\section{Copyright}

(c) The Author(s) 2021.

\section{References}

1. Adam R, Karam V, Cailliez V, O'Grady JG, Mirza D, Cherqui D, et al. 2018 Annual Report of the European Liver Transplant Registry (ELTR)-50-year evolution of liver transplantation. Transpl Int. 2018;31:1293-317.

2. Kim WR, Lake JR, Smith JM, Schladt DP, Skeans MA, Harper AM, et al. OPTN/SRTR 2016 annual data report: liver. Am J Transplant. 2018;18 Suppl 1:172-253.

3. Jun DW, Kim SG, Park SH, Jin SY, Lee JS, Lee JW, et al. External validation of the nonalcoholic fatty liver disease fibrosis score for assessing advanced fibrosis in Korean patients. J Gastroenterol Hepatol. 2017;32:1094-9.

4. Futagawa Y, Terasaki PI, Waki K, Cai J, Gjertson DW. No improvement in long-term liver transplant graft survival in the last decade: an analysis of the UNOS data. Am J Transplant. 2006;6:1398-406.

5. Watt KD, Pedersen RA, Kremers WK, Heimbach JK, Charlton MR. Evolution of causes and risk factors for mortality post-liver transplant: results of the NIDDK long-term follow-up study. Am J Transplant. 2010;10:1420-7.

6. Carenco C, Assenat E, Faure S, Duny Y, Danan G, Bismuth M, et al. Tacrolimus and the risk of solid cancers after liver transplant: a dose effect relationship. Am J Transplant. 2015;15:678-86.

7. VanWagner LB, Lapin B, Skaro AI, Lloyd-Jones DM, Rinella ME. Impact of renal impairment on cardiovascular disease mortality after liver transplantation for nonalcoholic steatohepatitis cirrhosis. Liver Int. 2015;35:2575-83.

8. Vanwagner LB, Bhave M, Te HS, Feinglass J, Alvarez L, Rinella ME. Patients transplanted for nonalcoholic steatohepatitis are at increased risk for postoperative cardiovascular events. Hepatology. 2012;56:1741-50.

9. VanWagner LB, Lapin B, Levitsky J, Wilkins JT, Abecassis MM, Skaro AI, et al. High early cardiovascular mortality after liver transplantation. Liver Transpl. 2014;20:1306-16.

10. Ampuero J, Romero-Gomez M. Influence of nonalcoholic fatty liver disease on cardiovascular disease. Gastroenterol Hepatologia. 2012;35:585-93.

11. Miura K, Ohnishi H. Role of gut microbiota and Toll-like receptors in nonalcoholic fatty liver disease. World J Gastroenterol. 2014;20:7381-91.

12. Brea A, Mosquera D, Martin E, Arizti A, Cordero JL, Ros E. Nonalcoholic fatty liver disease is associated with carotid atherosclerosis: a case-control study. Arterioscler Thromb Vasc biol. 2005;25:1045-50. 
13. Kim D, Choi SY, Park EH, Lee W, Kang JH, Kim W, et al. Nonalcoholic fatty liver disease is associated with coronary artery calcification. Hepatology. 2012;56:605-13.

14. Puchner SB, Lu MT, Mayrhofer T, Liu T, Pursnani A, Ghoshhajra BB, et al. High-risk coronary plaque at coronary CT angiography is associated with nonalcoholic fatty liver disease, independent of coronary plaque and stenosis burden: results from the ROMICAT II trial. Radiology. 2015;274:693-701.

15. Ampuero J, Gallego-Duran R, Romero-Gomez M. Association of NAFLD with subclinical atherosclerosis and coronary-artery disease: meta-analysis. Rev Esp Enferm Dig. 2015;107:10-6.

16. Fracanzani AL, Tiraboschi S, Pisano G, Consonni D, Baragetti A, Bertelli C, et al. Progression of carotid vascular damage and cardiovascular events in nonalcoholic fatty liver disease patients compared to the general population during 10 years of follow-up. Atherosclerosis. 2016;246:208-13.

17. Lonardo A, Nascimbeni F, Mantovani A, Targher G. Hypertension, diabetes, atherosclerosis and NASH: cause or consequence? J Hepatol. 2018;68:335-52.

18. Ekstedt M, Hagstrom H, Nasr P, Fredrikson M, Stal P, Kechagias S, et al. Fibrosis stage is the strongest predictor for disease-specific mortality in NAFLD after up to 33 years of follow-up. Hepatology. 2015;61:1547-54.

19. Kardashian AA, Dodge JL, Roberts J, Brandman D. Weighing the risks: morbid obesity and diabetes are associated with increased risk of death on the liver transplant waiting list. Liv Int. 2018;38:553-63.

20. European Association for the Study of the Liver (EASL), European Association for the Study of Disease (EASD), European Association for the Study of Oesity (EASO). EASL-EASD-EASO Clinical Practice Guidelines for the management of nonalcoholic fatty liver disease. J Hepatol. 2016;64:1388-402.

21. European Association for the Study of the Liver, Asociacion Latinoamericana para el Estudio del H. EASL-ALEH Clinical Practice Guidelines: non-invasive tests for evaluation of liver disease severity and prognosis. J Hepatol. 2015;63:237-64.

22. Ballestri S, Nascimbeni F, Baldelli E, Marrazzo A, Romagnoli D, Lonardo A. NAFLD as a sexual dimorphic disease: role of gender and reproductive status in the development and progression of nonalcoholic fatty liver disease and inherent cardiovascular risk. Adv Ther. 2017;34:1291-326.

23. Lonardo A, Nascimbeni F, Ballestri S, Fairweather D, Win S, Than TA, et al. Sex differences in nonalcoholic fatty liver disease: state of the art and identification of research gaps. Hepatology. 2019;70:1457-69.

24. Kim HJ, Lim CW, Lee JH, Park HB, Suh Y, Cho YH, et al. Gender-based differences in the relationship between fatty liver disease and atherosclerosis. Cardiovasc J Afr. 2016;27:281-6.

25. Labenz C, Huber Y, Michel M, Nagel M, Galle PR, Kostev K, et al. Impact of NAFLD on the incidence of cardiovascular diseases in a primary care population in germany. Dig Dis Sci. 2020;65:2112-9.

26. Niederseer D, Wernly S, Bachmayer S, Wernly B, Bakula A, Huber-Schonauer U, et al. Diagnosis of nonalcoholic fatty liver disease (NAFLD) is independently associated with cardiovascular risk in a large austrian screening cohort. J Clin Med. 2020;9:1065.

27. Kim MK, Ahn CW, Nam JS, Kang S, Park JS, Kim KR. Association between nonalcoholic fatty liver disease and coronary artery calcification in postmenopausal women. Menopause. 2015;22:1323-7.

28. Allen AM, Therneau TM, Mara KC, Larson JJ, Watt KD, Hayes SN, et al. Women with nonalcoholic fatty liver disease lose protection against cardiovascular disease: a longitudinal cohort study. Ame J Gastroenterol. 2019;114:1764-71.

29. Khalid YS, Dasu NR, Suga H, Dasu KN, Reja D, Shah A, et al. Increased cardiovascular events and mortality in females with NAFLD: a meta-analysis. Am J Cardiovasc Dis. 2020;10:258-71.

30. Kwong AJ, Devuni D, Wang C, Boike J, Jo J, VanWagner L, et al. Outcomes of liver transplantation among older recipients with nonalcoholic steatohepatitis in a large multicenter US cohort: the re-evaluating age limits in transplantation consortium. Liver Transpl. 2020;26:1492-503. 
31. Noureddin M, Vipani A, Bresee C, Todo T, Kim IK, Alkhouri N, et al. NASH leading cause of liver transplant in women: updated analysis of indications for liver transplant and ethnic and gender variances. Ame J Gastroenterol. 2018;113:1649-59.

32. VanWagner LB, Harinstein ME, Runo JR, Darling C, Serper M, Hall S, et al. Multidisciplinary approach to cardiac and pulmonary vascular disease risk assessment in liver transplantation: an evaluation of the evidence and consensus recommendations. Am J Transplant. 2018;18:30-42.

33. VanWagner LB, Serper M, Kang R, Levitsky J, Hohmann S, Abecassis M, et al. Factors associated with major adverse cardiovascular events after liver transplantation among a national sample. Am J Transplant. 2016;16:2684-94.

34. Konerman MA, Fritze D, Weinberg RL, Sonnenday CJ, Sharma P. Incidence of and risk assessment for adverse cardiovascular outcomes after liver transplantation: a systematic review. Transplantation. 2017;101:1645-57.

35. Konerman MA, Price JC, Campbell CY, Eluri S, Gurakar A, Hamilton J, et al. Pre-liver transplant transthoracic echocardiogram findings and 6-month post-transplant outcomes: a case-control analysis. Ann Transplant. 2016;21:416-27.

36. Alves BC, Bruch-Bertani JP, Galinatti CBM, Garbin CC, Alvares-da-Silva MR, Dall'Alba V. Obesity, dynapenia and high cardiovascular risk co-exist in post-liver transplant setting: results of a cross-sectional study. Clin Res Hepatol Gastroenterol. 2019;43:140-7.

37. Pisano G, Donato MF, Consonni D, Oberti G, Borroni V, Lombardi R, et al. High prevalence of early atherosclerotic and cardiac damage in patients undergoing liver transplantation: preliminary results. Dig Liver Dis. 2020;52:84-90.

38. Perito ER, Phelps A, Vase T, Feldstein VA, Lustig RH, Rosenthal P. Subclinical atherosclerosis in pediatric liver transplant recipients: carotid and aorta intima-media thickness and their predictors. J Pediatr. 2018;193:119-27.

39. VanWagner LB, Ning H, Whitsett M, Levitsky J, Uttal S, Wilkins JT, et al. A point-based prediction model for cardiovascular risk in orthotopic liver transplantation: the CAR-OLT score. Hepatology. 2017;66:1968-79.

40. Fussner LA, Heimbach JK, Fan C, Dierkhising R, Coss E, Leise MD, et al. Cardiovascular disease after liver transplantation: when, what, and who is at risk. Liver Transpl. 2015;21:889-96.

41. Izzy M, VanWagner LB, Lee SS, Altieri M, Angirekula M, Watt KD. Understanding and managing cardiovascular outcomes in liver transplant recipients. Curr Opin Organ Transplant. 2019;24:148-55.

42. Myers RP, Lee SS. Cirrhotic cardiomyopathy and liver transplantation. Liver Transpl. 2000;6:S44-52.

43. Eimer MJ, Wright JM, Wang EC, Kulik L, Blei A, Flamm S, et al. Frequency and significance of acute heart failure following liver transplantation. Am J Cardiol. 2008;101:242-4.

44. Dowsley TF, Bayne DB, Langnas AN, Dumitru I, Windle JR, Porter TR, et al. Diastolic dysfunction in patients with end-stage liver disease is associated with development of heart failure early after liver transplantation. Transplantation. 2012;94:646-51.

45. Josefsson A, Fu M, Bjornsson E, Kalaitzakis E. Prevalence of pre-transplant electrocardiographic abnormalities and post-transplant cardiac events in patients with liver cirrhosis. BMC Gastroenterol. 2014;14:65.

46. Qureshi W, Mittal C, Ahmad U, Alirhayim Z, Hassan S, Qureshi S, et al. Clinical predictors of post-liver transplant new-onset heart failure. Liver Transpl. 2013;19:701-10.

47. Mittal C, Qureshi W, Singla S, Ahmad U, Huang MA. Pre-transplant left ventricular diastolic dysfunction is associated with post transplant acute graft rejection and graft failure. Dig Dis Sci. 2014;59:674-80.

48. Sonny A, Govindarajan SR, Jaber WA, Cywinski JB. Systolic heart failure after liver transplantation: incidence, predictors, and outcome. Clin Transplant. 2018;32:e13199. 
49. Kia L, Shah SJ, Wang E, Sharma D, Selvaraj S, Medina C, et al. Role of pretransplant echocardiographic evaluation in predicting outcomes following liver transplantation. Am J Transplant. 2013;13:2395-401.

50. Izzy M, Oh J, Watt KD. Cirrhotic cardiomyopathy after transplantation: neither the transient nor innocent bystander. Hepatology. 2018;68:2008-15.

51. Liu H, Jayakumar S, Traboulsi M, Lee SS. Cirrhotic cardiomyopathy: implications for liver transplantation. Liver transpl. 2017;23:826-35.

52. Izzy M, VanWagner LB, Lin G, Altieri M, Findlay JY, Oh JK, et al. Redefining cirrhotic cardiomyopathy for the modern era. Hepatology. 2020;71:334-45.

53. Mohamed R, Forsey PR, Davies MK, Neuberger JM. Effect of liver transplantation on QT interval prolongation and autonomic dysfunction in end-stage liver disease. Hepatology. 1996;23:1128-34.

54. Bargehr J, Trejo-Gutierrez JF, Patel T, Rosser B, Aranda-Michel J, Yataco ML, et al. Preexisting atrial fibrillation and cardiac complications after liver transplantation. Liver Transpl. 2015;21:314-20.

55. Fleisher LA, Fleischmann KE, Auerbach AD, Barnason SA, Beckman JA, Bozkurt B, et al. 2014 ACC/ AHA guideline on perioperative cardiovascular evaluation and management of patients undergoing noncardiac surgery: executive summary: a report of the American College of Cardiology/American Heart Association Task Force on Practice Guidelines. Circulation. 2014;130:2215-45.

56. Anstee QM, Mantovani A, Tilg H, Targher G. Risk of cardiomyopathy and cardiac arrhythmias in patients with nonalcoholic fatty liver disease. Nat Rev Gastroenterol Hepatol. 2018;15:425-39.

57. VanWagner LB, Ning H, Whitsett M, Levitsky J, Uttal S, Wilkins JT, et al. A point-based prediction model for cardiovascular risk in orthotopic liver transplantation: the CAR-OLT score. Hepatology. 2017;66:1968-79.

58. D’Agostino Sr RB, Vasan RS, Pencina MJ, Wolf PA, Cobain M, Massaro JM, et al. General cardiovascular risk profile for use in primary care: the Framingham Heart Study. Circulation. 2008;117:743-53.

59. Lloyd-Jones DM, Huffman MD, Karmali KN, Sanghavi DM, Wright JS, Pelser C, et al. Estimating longitudinal risks and benefits from cardiovascular preventive therapies among medicare patients: the million hearts longitudinal ASCVD risk assessment tool: a special report from the American Heart Association and American College of Cardiology. J Am Coll Cardiol. 2017;69:1617-36.

60. Ridker PM, Paynter NP, Rifai N, Gaziano JM, Cook NR. C-reactive protein and parental history improve global cardiovascular risk prediction: the Reynolds Risk Score for men. Circulation. 2008;118:2243-51.

61. Assmann G, Cullen P, Schulte H. Simple scoring scheme for calculating the risk of acute coronary events based on the 10-year follow-up of the prospective cardiovascular Münster (PROCAM) study. Circulation. 2002;105:310-5.

62. Conroy RM, Pyorala K, Fitzgerald AP, Sans S, Menotti A, De Backer G, et al. Estimation of ten-year risk of fatal cardiovascular disease in Europe: the SCORE project. Eur Heart J. 2003;24:987-1003.

63. Roccaro GA, Goldberg DS, Hwang WT, Judy R, Thomasson A, Kimmel SE, etal. Sustained posttransplantation diabetes is associated with long-term major cardiovascular events following liver transplantation. Am J Transplant. 2018;18:207-15.

64. Al Nasser Y, Moura MC, Mertens L, McCrindle BW, Parekh RS, Ng VL, et al. Subclinical cardiovascular changes in pediatric solid organ transplant recipients: a systematic review and meta-analysis. Pediatr transplant. 2016;20:530-9.

65. Siirtola A, Kallio T, Ala-Houhala M, Lehtimaki T, Solakivi T, Antikainen M, et al. Carotid intima-media thickness after pediatric renal or liver transplantation at high-resolution B-mode ultrasonography. Transplant Proc. 2010;42:1695-8.

66. Delucchi A, Dinamarca H, Gainza H, Whitttle C, Torrealba I, Iniguez G. Carotid intima-media thickness as a cardiovascular risk marker in pediatric end-stage renal disease patients on dialysis and in renal transplantation. Transplant Proc. 2008;40:3244-6. 
67. Mitsnefes MM, Kimball TR, Witt SA, Glascock BJ, Khoury PR, Daniels SR. Abnormal carotid artery structure and function in children and adolescents with successful renal transplantation. Circulation. 2004;110:97-101.

68. Krmar RT, Balzano R, Jogestrand T, Cedazo-Minguez A, Englund MS, Berg UB. Prospective analysis of carotid arterial wall structure in pediatric renal transplants with ambulatory normotension and in treated hypertensive recipients. Pediatr Transplant. 2008;12:412-9.

69. Bilginer Y, Ozaltin F, Basaran C, Aki TF, Karabulut E, Duzova A, et al. Carotid intima-media thickness in children and young adults with renal transplant: internal carotid artery vs. common carotid artery. Pediatr transplant. 2007;11:888-94.

70. Litwin M, Wuhl E, Jourdan C, Trelewicz J, Niemirska A, Fahr K, et al. Altered morphologic properties of large arteries in children with chronic renal failure and after renal transplantation. J Am Soc Nephrol. 2005;16:1494-500.

71. Basiratnia M, Fazel M, Lotfi M, Hosseini Al-Hashemi G, Fallahzadeh MH, Derakhshan A, et al. Subclinical atherosclerosis and related risk factors in renal transplant recipients. Pediatr Nephrol. 2010;25:343-8.

72. Memaran N, Borchert-Morlins B, Schmidt BMW, Sugianto RI, Wilke H, Blote R, et al. High burden of subclinical cardiovascular target organ damage after pediatric liver transplantation. Liver Transpl. 2019;25:752-62.

73. Vinaixa C, Selzner N, Berenguer M. Fat and liver transplantation: clinical implications. Transpl Int. 2018;31:828-37.

74. Rinella ME, Alonso E, Rao S, Whitington P, Fryer J, Abecassis M, et al. Body mass index as a predictor of hepatic steatosis in living liver donors. Liver Transpl. 2001;7:409-14.

75. Selzner M, Rudiger HA, Sindram D, Madden J, Clavien PA. Mechanisms of ischemic injury are different in the steatotic and normal rat liver. Hepatology. 2000;32:1280-8.

76. Selzner N, Selzner M, Jochum W, Amann-Vesti B, Graf R, Clavien PA. Mouse livers with macrosteatosis are more susceptible to normothermic ischemic injury than those with microsteatosis. J Hepatol. 2006;44:694-701.

77. de Graaf EL, Kench J, Dilworth P, Shackel NA, Strasser SI, Joseph D, et al. Grade of deceased donor liver macrovesicular steatosis impacts graft and recipient outcomes more than the Donor Risk Index. J Gastroenterol Hepatol. 2012;27:540-6.

78. Spitzer AL, Lao OB, Dick AA, Bakthavatsalam R, Halldorson JB, Yeh MM, et al. The biopsied donor liver: incorporating macrosteatosis into high-risk donor assessment. Liver Transpl. 2010;16:874-84.

79. Cieslak B, Lewandowski Z, Urban M, Ziarkiewicz-Wroblewska B, Krawczyk M. Microvesicular liver graft steatosis as a risk factor of initial poor function in relation to suboptimal donor parameters. Transplant Proc. 2009;41:2985-8.

80. Kulik U, Lehner F, Klempnauer J, Borlak J. Primary non-function is frequently associated with fatty liver allografts and high mortality after re-transplantation. Liver Int. 2017;37:1219-28.

81. Andert A, Ulmer TF, Schoning W, Kroy D, Hein M, Alizai PH, et al. Grade of donor liver microvesicular steatosis does not affect the postoperative outcome after liver transplantation. Hepatobiliary Pancreat Dis Int. 2017;16:617-23.

82. Jamieson RW, Zilvetti M, Roy D, Hughes D, Morovat A, Coussios CC, et al. Hepatic steatosis and normothermic perfusion-preliminary experiments in a porcine model. Transplantation. 2011;92:289-95.

83. Bhanji RA, Watt KD. Fatty allograft and cardiovascular outcomes after liver transplantation. Liver Transpl. 2017;23:S76-80.

84. Contos MJ, Cales W, Sterling RK, Luketic VA, Shiffman ML, Mills AS, et al. Development of nonalcoholic fatty liver disease after orthotopic liver transplantation for cryptogenic cirrhosis. Liver Transpl. 2001;7:363-73. 
85. Dumortier J, Giostra E, Belbouab S, Morard I, Guillaud O, Spahr L, et al. Nonalcoholic fatty liver disease in liver transplant recipients: another story of "seed and soil". Am J Gastroenterol. 2010;105:613-20.

86. Hejlova I, Honsova E, Sticova E, Lanska V, Hucl T, Spicak J, et al. Prevalence and risk factors of steatosis after liver transplantation and patient outcomes. Liver Transpl. 2016;22:644-55.

87. Vallin M, Guillaud O, Boillot O, Hervieu V, Scoazec JY, Dumortier J. Recurrent or de novo nonalcoholic fatty liver disease after liver transplantation: natural history based on liver biopsy analysis. Liver Transpl. 2014;20:1064-71.

88. Seo S, Maganti K, Khehra M, Ramsamooj R, Tsodikov A, Bowlus C, et al. De novo nonalcoholic fatty liver disease after liver transplantation. Liver Transpl. 2007;13:844-7.

89. Losurdo G, Castellaneta A, Rendina M, Carparelli S, Leandro G, Di Leo A. Systematic review with meta-analysis: de novo fatty liver disease in liver-transplanted patients. Aliment Pharmacol Ther. 2018;47:704-14.

90. Idowu MO, Chhatrala R, Siddiqui MB, Driscoll C, Stravitz RT, Sanyal AJ, et al. De novo hepatic steatosis drives atherogenic risk in liver transplantation recipients. Liver Transpl. 2015;21:1395-402.

91. Yalamanchili K, Saadeh S, Klintmalm GB, Jennings LW, Davis GL. Nonalcoholic fatty liver disease after liver transplantation for cryptogenic cirrhosis or nonalcoholic fatty liver disease. Liver Transpl. 2010;16:431-9.

92. Bhati C, Idowu MO, Sanyal AJ, Rivera M, Driscoll C, Stravitz RT, et al. Long-term outcomes in patients undergoing liver transplantation for nonalcoholic steatohepatitis-related cirrhosis. Transplantation. 2017;101:1867-74.

93. Coss E, Watt KD, Pedersen R, Dierkhising R, Heimbach JK, Charlton MR. Predictors of cardiovascular events after liver transplantation: a role for pretransplant serum troponin levels. Liver transpl. 2011;17:23-31.

94. Targher G, Bertolini L, Padovani R, Rodella S, Tessari R, Zenari L, et al. Prevalence of nonalcoholic fatty liver disease and its association with cardiovascular disease among type 2 diabetic patients. Diabetes Care. 2007;30:1212-8.

95. Dureja P, Mellinger J, Agni R, Chang F, Avey G, Lucey M, et al. NAFLD recurrence in liver transplant recipients. Transplantation. 2011;91:684-9.

96. Nagai S, Collins K, Chau LC, Safwan M, Rizzari M, Yoshida A, et al. Increased risk of death in first year after liver transplantation among patients with nonalcoholic steatohepatitis vs liver disease of other etiologies. Clin Gastroenterol Hepatol. 2019;17:2759-68.e5.

97. Gitto S, Vukotic R, Vitale G, Pirillo M, Villa E, Andreone P. Nonalcoholic steatohepatitis and liver transplantation. Dig Liver Dis. 2016;48:587-91.

98. Kouz J, Vincent C, Leong A, Dorais M, Rakel A. Weight gain after orthotopic liver transplantation: is nonalcoholic fatty liver disease cirrhosis a risk factor for greater weight gain? Liver Transpl. 2014;20:1266-74.

99. D’Avola D, Cuervas-Mons V, Marti J, Ortiz de Urbina J, Llado L, Jimenez C, et al. Cardiovascular morbidity and mortality after liver transplantation: the protective role of mycophenolate mofetil. Liver Transpl. 2017;23:498-509.

100. Dongiovanni P, Petta S, Maglio C, Fracanzani AL, Pipitone R, Mozzi E, et al. Transmembrane 6 superfamily member 2 gene variant disentangles nonalcoholic steatohepatitis from cardiovascular disease. Hepatology. 2015;61:506-14.

101. Akoglu B, Kindl P, Weber N, Trojan J, Caspary WF, FaustD. Polymorphisms in the methylenetetrahydrofolate reductase gene are determinant for vascular complications after liver transplantation. Eur J Clin Nutr. 2008;62:430-5.

102. De Vincentis A, Mancina RM, Pihlajamaki J, Mannisto V, Petta S, Dongiovanni P, et al. Genetic variants in the MTHFR are not associated with fatty liver disease. Liver Int. 2020;40:1934-40.

103. Dongiovanni P, Valenti L. Genetics of nonalcoholic fatty liver disease. Metabolism. 2016;65:1026-37. 
104. Liu ZT, Chen TC, Lu XX, Cheng J, Xie HY, Zhou L, et al. PNPLA3 I148M variant affects nonalcoholic fatty liver disease in liver transplant recipients. World J Gastroenterol. 2015;21:10054-6.

105. Piazza NA, Singal AK. Frequency of cardiovascular events and effect on survival in liver transplant recipients for cirrhosis due to alcoholic or nonalcoholic steatohepatitis. Exp Clin Transplant. 2016;14:79-85.

106. Wang X, Li J, Riaz DR, Shi G, Liu C, Dai Y. Outcomes of liver transplantation for nonalcoholic steatohepatitis: a systematic review and meta-analysis. Clin Gastroenterol Hepatol. 2014;12:394-402.

107. Targher G, Byrne CD, Lonardo A, Zoppini G, Barbui C. Nonalcoholic fatty liver disease and risk of incident cardiovascular disease: a meta-analysis. J Hepatology. 2016;65:589-600. 